


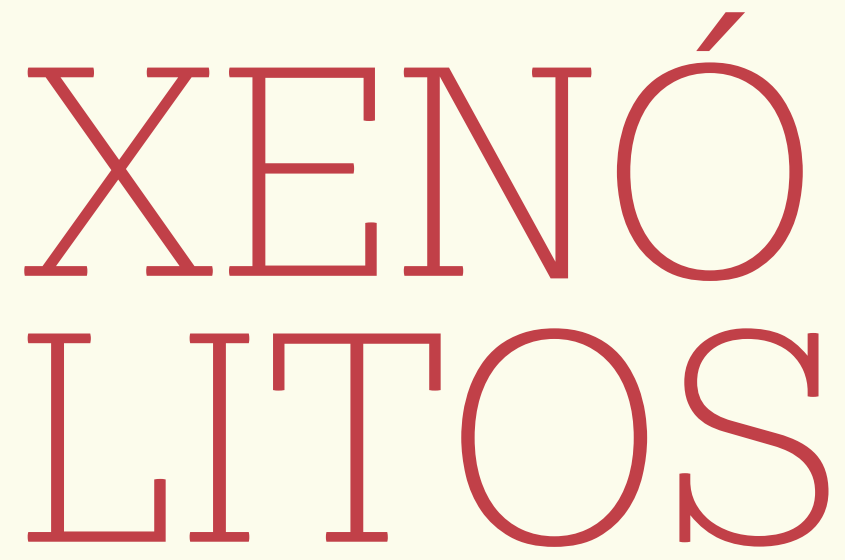

Fragmento de rocha preexistente, envolvido numa rocha magmática. 


\section{"AQUELES QUE DELA COMERAM TORNARAM-SE OS TCHIERKO, OS FEITICEIROS DEVORADORES DE ALMAS"}

- ANA LUIZA DE OLIVEIRA E SILVA

\section{RESUMO}

Pretendemos dar a conhecer, por meio da tradução, um conto que circulou oralmente na região da África ocidental. A narrativa, cujos elementos permitem relacioná-la ao povo Zarma-Songai, possui origens imemoriais e nos permite vislumbrar alguns aspectos do universo mágico-religioso de povos daquela região, notadamente, a origem lendária dos chamados "feiticeiros devoradores de almas".

Palavras-chave: Tradição oral, Universo mágico-religioso, África ocidental.

\section{ABSTRACT}

Through the means of translation, we aim to bring forth a West African oral tale. The elements of this immemorial story allow us to relate it to the Zarma-Songhay people. They also grant us contact with the magical-religious universe of those West African peoples, especially, the legendary origin of the sorcerers known as "eaters of souls".

Keywords: Oral tradition, Magical-religious universe, West Africa.

\section{INTRODUÇÃO}

presentaremos aqui, traduzido para o português e em sua versão
original, um conto da tradição oral do Sael, no ocidente africano.
Intitulada Fati Dara ou l'origine de la sorcellerie [Fati Dara, ou a origem da feitiçaria], a narrativa foi publicada no ano de 1976, em língua francesa, pelo intelectual Boubou Hama, no sexto tomo de sua coletânea de histórias chamada Contes et légendes du Niger [Contos e lendas 
do Níger] ${ }^{1}$. O próprio título da compilação pode ser relativizado pois, apesar de a época da publicação inserir-se no contexto do pós-independência dos países africanos - que no caso do Níger deu-se em 1960 -, as sessenta e sete histórias que compõem os tomos da coletânea fazem parte da tradição oral de povos do ocidente da África que, por sua vez, transitavam pelo território sem respeitar fronteiras, delimitadas arbitrariamente pelos colonizadores.

Tais povos passaram por períodos de nomadismo, como os Tuaregues, ainda conhecidos por seu caráter transitório, e períodos de sedentarismo, chegando mesmo, alguns, como os Songai, a constituírem reinos e impérios. ${ }^{2} \mathrm{O}$ conto sobre o qual nos debruçamos possui indicações de ter origem Zarma-Songai, apesar de ser impossível - e mesmo inútil delimitar categoricamente uma origem única para histórias imemoriais que circulavam oralmente. Por outro lado, alguns elementos sugerem por onde aquele conto transitou, como a nomenclatura de determinadas árvores em língua Zarma e a denominação de certos feiticeiros - sendo o próprio objetivo do conto determinar sua origem lendária - presentes no universo mágico-religioso Songai.

Em relação a este, cujo arcabouço de crenças é bastante vasto e complexo, convém apontar rapidamente a crença em uma força vital [hunde], que diferencia os seres animados dos não-animados, e em um duplo [biya] que acompanha alguns seres, como os humanos. Geralmente traduzido como "alma", apesar de suas especificidades e diferenças em relação à noção cristã, é pelo conceito de biya que os Songai compreendem o reflexo no espelho, os sonhos e pesadelos, as possessões, as visões e a morte. No mesmo conjunto de crenças, tem-se a presença dos "feiticeiros devoradores de almas" [les tyarkaw mangeurs de biya] $]^{3}$, cuja origem é explicada pelo conto que aqui traduzimos. Nele, a palavra utilizada é tchierko, foneticamente similar ao tyarkaw utilizado por Jean Rouch ao referir-se ao mesmo personagem. Tal diferença se deve à falta de registros escritos entre os povos em questão, cuja ausência de sinais gráficos para simbolizar sons - apesar de existirem exceções - é notória.

Em relação a outros elementos presentes no conto, vale notar a presença de um gênio, ser sobrenatural que, no entanto, relaciona-se com os humanos, denotando a fluidez, típica em sociedades africanas tradicionais, entre as esferas do mundo natural e do mundo sobrenatural. Por outro lado, não sendo prerrogativa apenas de tais culturas, os gênios também são parte constituinte do universo islâmico - estando presentes no próprio Corão $0^{4}$, cuja presença se fez sentir na África ocidental a partir do século VIII, quando inicia seu prolongado avanço pelo território. $\mathrm{O}$ conto ainda traz outros aspectos que marcam a presença
[1] HAMA, Boubou. Fati Dara ou l'origine de la sorcellerie. In: Contes et légendes du Niger. Tome VI. Paris: Présence Africaine, 1976.

[2] É importante atentar para o que Hernandez aponta no sentido de "identificar as principais organizações sociais e políticas na África pré-colonial, de 1500 a 1800, genericamente denominadas 'reinos', 'Estados' e 'impérios', significando ora sistemas de governo, ora modos de centralização ou descentralização administrativa"; ou seja, mesmo aqueles termos podem ser relativizados de acordo com a época tratada. HERNANDEZ, Leila Maria Gonçalves Leite. A África na sala de aula: visita à história contemporânea. $4^{a}$ ed. São Paulo: Selo Negro, 2008, p. 33.

[3] Todas essas noções são mais detalhadamente explicadas e estão presentes em estudos do eminente etnólogo francês Jean Rouch, especificamente em: ROUCH, Jean. La religion et la magie songhay. [1960] $2^{\mathrm{e}}$ édition revue et augmentée. Bruxelles : Éditions de l'Université de Bruxelles, 1989, pp. 34-38.

[4] São diversos os momentos nos quais os gênios [jinns] são referenciados no Corão. Como exemplo, cabe citar o próprio título da 72a Sura: A Sura dos Jinns [Suratu Al-Jinn]. Cf. o NOBRE ALCORÃo. Tradução de sentido para a língua portuguesa realizada por Dr. Helmi NASR, professor de Estudos Árabes e Islâmicos na Universidade de São Paulo. São Paulo: Centro Islâmico no Brasil, s/d 
[5] Dentro do islamismo, os marabus são letrados, homens de Deus, guias religiosos e até mesmo temporais, podendo ser professores nas escolas corânicas. Seus alunos, com idades compreendidas entre os cinco e os quinze anos, são chamados de garibus, morikafalander em língua bambara e talibé em fula. De acordo com o professor Dr. Paulo Daniel Farah, do Departamento de Línguas Orientais da FFLCH/ USP, em língua árabe, a palavra "marabu" refere-se a forte ou fortaleza, sendo o marabu uma figura caracterizada pela piedade. do Islã, como a invocação de Deus (Allah) e a presença de marabus ${ }^{5}$, o que denota a interpenetração entre elementos islâmicos e elementos de culturas tradicionais de África.

Apesar de a narrativa que apresentamos ser uma pequena parte da obra compilada por Boubou Hama, e ainda menor se comparada a toda a gama de tradições orais do oeste africano, ela nos permite um vislumbre de um extenso e maravilhoso universo cultural. Através do conto Fati Dara, ou a origem da feitiçaria, procuramos contribuir para a divulgação deste universo; a intenção aqui não é analisar seus elementos, mas simplesmente dá-lo a conhecer.

No tocante à tradução, optamos por priorizar o sentido do conto em sua versão em língua francesa. Também buscamos manter o aspecto da oralidade nas falas dos personagens, o que acreditamos produzir uma maior aproximação com a maneira pela qual a história era contada em sua(s) versão(ões) oral(is). Por fim, e com o mesmo intuito, procuramos manter rimas e repetições, quando ocorrerem. 


\section{FATI DARA, OU A ORIGEM DA FEITIÇARIA}

Há muito, muito tempo, na origem dos tempos, vivia em uma vila Fati Dara, Fati da pele de cobre claro. Ela era alegre e bela. Sua pele era incomparável, como a lua rosada que se levanta sobre um firmamento sem nuvens. Seus dentes maravilhosamente brancos tinham a cor do leite e seus longos cabelos ondulados lhe caíam sobre os ombros. Bem arrumada em suas vestes de seda e veludo, ornada com seus braceletes de ouro e prata e com suas joias de diamantes cintilantes, Fati era a estrela da região. Ela havia se tornado um espelho que atraía em sua esteira os reis, os príncipes, os ricos e os grandes guerreiros, que corriam para pedir sua mão a seus pais.

Mas, infelizmente, Fati era uma garota difícil. Tinha na cabeça três enigmas e queria se casar apenas com o homem que fosse capaz de desvendá-los. Eis os enigmas:

$1^{\circ}$ - Qual é a única mulher do mundo que não tem co-esposa $a^{6}$ que não a admite e a quem ninguém sonha propor uma?

$2^{\circ}$ - Qual é o único ser do mundo que se esconde na água quando chove?

3ํ- Qual é a única coisa no mundo mais rápida que o raio e que um piscar de olhos?

Os jovens, os príncipes, os reis, os ricos, os grandes guerreiros: todos desfilaram perante Fati, a bela garota. Alguns foram rejeitados por causa de suas qualidades físicas desagradáveis. Todos tropeçaram nos três enigmas. Todos foram recusados.

Um gênio, após aqueles fracassos, decidiu desposar Fati Dara. Metamorfoseando-se, trocou sua natureza de ogro pela de um jovem, cuja beleza anuviava a da garota.

O gênio teve muita dificuldade em encontrá-la, pois cada morador da vila que ele abordava lhe dizia:

- Você é belo, muito belo, mas, como os outros candidatos, você tropeçará nos três enigmas da jovem.

O gênio não se deixou desencorajar por tais palavras. Persistiu e terminou por encontrar Fati Dara. Esta, vendo que o jovem era muito belo, estava prestes a conceder-lhe a mão, quando sua mãe lembrou-lhe dos três enigmas:

- Coloque o estrangeiro à prova: peça que te responda seus três enigmas.

[6] As sociedades às quais os contos se referem são poligâmicas; assim, os filhos convivem com a própria mãe e com a(s) outra(s) esposa(s) do pai, que é(são) chamada(s), nos termos franceses utilizados por Boubou Hama, de petite mère(s) pelas crianças e de co-épouse(s) pe$\mathrm{la}(\mathrm{s})$ outra(s) esposa(s). 
[7] "Griot é o nome dado pelos franceses ao diéli que entre os mambara significa 'contador de histórias. A tempo: diéli é quem tem a força vital." HERNANDEZ, Op. Cit., p. 29, nota 15. E ainda: "Mas afinal, quem são os griots? São trovadores, menestréis, contadores de histórias e animadores públicos para os quais a disciplina da verdade perde rigidez, sendo-Ihe facultada uma linguagem mais livre. Ainda assim, sobressai o compromisso com a verdade, sem o qual perderiam a capacidade de atuar para manter a harmonia e a coesão grupais, com base em uma função genealógica de fixar as mitologias familiares no âmbito de sociedades tradicionais." Id. Ibid., p. 30.

[8] Feminino de griot. Convém aqui lembrarmos de um comentário da professora Drạ. Leila Hernandez durante uma aula da disciplina "Elites Africanas", lecionada em 2013 no Departamento de História da FFLCH/USP, de que hoje os países africanos contam com a presença das chamadas griotes, que se apresentam em shows similares aos de cabaré, o que denota que tais figuras, inicialmente compreendidas como intérpretes e depositários das tradições, parecem ter sofrido drásticas mudanças.
Mas a jovem, frente a ele, ficou sem palavras. Sob o efeito de um amor à primeira vista, que lhe inibia qualquer reação, ficou indefesa diante daquele belo estrangeiro.

Pela segunda vez, a mãe de Fati lembrou-lhe dos enigmas através dos quais ela testava a inteligência de seus pretendentes.

Recordando-se de seu princípio, teve medo de colocar os enigmas ao belo estrangeiro, com medo de perdê-lo caso ele não respondesse corretamente.

Sua mãe, intervindo uma terceira vez, disse:

- Minha filha, seu princípio é sábio e deve dominar sua escolha. Peça que o estrangeiro te responda os três enigmas. Assim, minha filha, você julgará sua inteligência.

Com muita hesitação, Fati lançou os três enigmas ao belo estrangeiro. Este, de uma inteligência incomum, respondeu:

1ํ - A única mulher do mundo que não tem co-esposa, que não a admite e a quem ninguém sonha propor uma "é o chefe". Este é sempre único.

$2^{\circ}$ - O único ser do mundo que se esconde sob a água quando chove é o sapo. Quando chove, ele se abriga sob uma poça d'água.

3o - A única coisa no mundo que é mais rápida que o raio e que um piscar de olhos é o pensamento, aquele que se direciona à mulher ou ao homem que amamos.

Entusiasmada, a mãe de Fati, que acompanhara a conversa entre a filha e o belo estrangeiro, gritou:

- É formidável! É formidável, minha filha, agora você tem um marido! Ele é o homem mais belo do mundo e sua inteligência é de uma vivacidade sem igual.

A mãe de Fati Dara percorreu a vila, anunciando:

- Minha filha encontrou um marido, um homem de uma beleza excepcional e de uma inteligência inigualável. Saiam, gente da vila, Fati Dara encontrou o homem que ela ama! Venham correndo, gente da vila! Venham correndo, vizinhos, velhos e velhas, griots ${ }^{7}$ e griotes $^{8}$ ! Venham aos montes assistir ao casamento da minha filha com um homem de inteligência sem igual e de uma beleza extraordinária. 
As pessoas da vila, os velhos e os garotos, assim como as garotas, os vizinhos e as vizinhas, os griots e as griotes, todos em festa, acorreram ao chamado da mãe de Fati Dara. Sua concessão ${ }^{9}$ ficou repleta de homens e de mulheres, de griots e de griotes em festa, de marabus exibindo grandes Corões abertos.

O casamento de Fati Dara foi celebrado em grande alegria. Nozesde-cola ${ }^{10}$, bubus ${ }^{11}$, vestimentas ${ }^{12}$ e lenços foram distribuídos aos griots, às griotes, aos velhos e às velhas, aos marabus, a todos os presentes, deslumbrados pela generosidade do belo estrangeiro.

Frente a tanta magnificência, a tantos carneiros, cabras, bois e camelos abatidos para festejar o casamento de sua filha, a mãe da garota exultou:

- Venham ver o marido da minha filha! Venham ver um homem de beleza sem igual, o homem mais inteligente do mundo, o mais generoso dos homens.Venham ver minha filha e seu marido, o casal mais bonito da terra.

O gênio, nessa atmosfera de festa e de fartura, viveu alguns dias com sua mulher, a bela e difícil Fati Dara.

Mas como tudo tem um fim, o belo estrangeiro obteve autorização para levar a esposa para sua casa. Colocou-a na garupa de seu cavalo e levou-a. No caminho, marido e mulher falaram de seu casamento, da vila, dos pretendentes malsucedidos que Fati Dara havia recusado, da mãe da garota, de suas lembranças e de sua lua de mel.

O sol levantara-se um pouco mais alto no céu quando os dois esposos transpuseram a fronteira da vila de Fati, depois da qual, atravessaram a savana e entraram em uma floresta espessa.

Fati Dara havia, há muito tempo, parado de falar e de responder a seu marido, particularmente eloquente no curso da viagem. Enfim, nas profundezas da floresta, o cavalo do belo estrangeiro parou em frente a uma gruta. Fati Dara desceu. Então, foi a vez de seu marido colocar os pés na terra. $O$ cavalo relinchou e se transformou em uma girafa. $O$ belo estrangeiro assobiou e se transformou em um gênio disforme, infecto, com dois chifres sobre a cabeça, cascos fendidos, unhas em forma de garras, presas longas como facões afiados, cílios e sobrancelhas que caíam sobre as bochechas como cabelos trançados e orelhas longas como as de um asno. Assim ele se apresentou a Fati Dara: em sua verdadeira natureza, sem máscaras, em sua realidade de gênio, de verdadeiro gênio que Fati, de tanto escolher, havia desposado para o melhor e para o pior.
[9] No original, concession, cujo significado em francês refere-se a uma terra atribuída, ou concedida, para ser explorada e trabalhada.

[10] A noz-de-cola era utilizada como moeda de troca e, por vezes, também entregue como presente, como citado, por exemplo, em outro conto de Boubou Hama: “... Toula était sage. Elle était tendre. Elle aimait, chaque matin, passer devant ma porte. Joyeuse, elle me jetait une noix de cola...". Hama, Boubou. Toula / La nouvelle. In: Contes et légendes du Niger. Tome I. Paris : Présence Africaine, 1972, p. 203. Por sua vez, Amadou Hampâté Bâ, além de citar o mesmo uso, também faz referência ao uso da noz-de-cola no ritual da circuncisão: Cf. HAMPĀTÉ BÂ, Amadou. Amkoullel, o menino fula. São Paulo: Palas Athena : Casa das Áfricas, 2003.

[11] Espécie de túnica solta utilizada por homens na África ocidental.

[12] A palavra aqui utilizada no original é pagne, que se refere a vestimentas de tecido, folhas ou palha, como tangas, saias ou sarongues, mas é difícil dizer qual o termo adequado para a região africana em questão. 
[13] "Brousse: formação estépica da África, caracterizada por vegetação rasteira de gramíneas misturada com algumas árvores $\mathrm{e}$ arbustos. Também qualquer área fora do perímetro da cidade. Em português, a palavra mais aproximada seria 'sertão'." HAMPÂTÉ BÂ. Op. Cit., p. 26, nota do tradutor."Courage, mon fils, je demeurerai, toujours, ton père compatissant, ton 'père de l'autre côté', ton 'père de la brousse'." HAMA, Boubou. Le secret / L'orphelin et le génie. In: Contes et légendes du Niger. Tome II.Paris: Présence Africaine, 1972, p. 35. Essa frase é acompanhada de uma nota de rodapé explicando que a palavra brousse se refere, no sentido figurado, a tudo que não é "da vila", referindo-se ao mundo invisível e seus espíritos.
Ao ver a terrível criatura, Fati Dara, tomada de pânico, chorou. Mas não gritou, apenas deixou que corressem lágrimas abundantes.

O monstro moveu seu corpo coberto de escamas, seus dentes longos como facões afiados, suas grandes orelhas de asno, seus cílios e sobrancelhas que caíam sobre as bochechas. Com os cascos fendidos afundados no solo, horroroso, ele disse à mulher:

- Mulher, não chore. Eu sou o rei da brousse ${ }^{13}$, você é a rainha e deve obedecer às minhas ordens. Você é minha mulher; portanto obrigada a viver comigo. A cada manhã, eu irei à caça e você ficará em casa cuidando da cozinha. Eu não gosto de traição. Você também não deve esquecer que está a seis meses de caminhada da sua vila, longe de qualquer socorro humano. Se você tentar fugir, eu cobrirei em uma hora a distância que você pode percorrer em quinze dias a pé. Então, minha querida, comporte-se e faça o que eu te mandar.

O gênio monstruoso retomou sua rotina diária. A cada manhã, ele saía para caçar e trazia um animal abatido, que entregava à sua mulher. Por falta de carne humana, ela então lhe cozinhava a carne do animal.

Por doze meses, a rotina doméstica teve seu curso. Durante esse tempo, a mãe de Fati, sem notícias da filha, perdeu a alegria. Ficava amuada em seu quarto e não saía mais. Inicialmente inquieta, acabou por se desesperar.

Farta de esperar, pegou uma semente de abóbora e a enfeitiçou. Antes de semeá-la no solo úmido, disse-lhe:

- Boa semente de abóbora, boa semente de Deus, eu vou te confiar à terra. Você vai crescer, boa semente, vai se tornar um caule. Do caule crescerá um galho, que rastejará pelo solo, longe, muito longe, até a casa de meu genro, até minha filha.

A mãe de Fati plantou a semente de abóbora. Esta cresceu. Seu caule frágil saiu da terra, lançou um galho rasteiro que se estendeu sobre o solo, longe, por quilômetros, muito longe pela brousse até o genro da mulher, até a gruta que servia de casa para sua filha.

Assim, em dois meses, a planta cobriu a distância que separava mãe e filha. A mãe seguiu o galho rastejante da abóbora por dias, noites, meses. Enfim, ela chegou à porta da gruta onde a garota estava reclusa. Esta, vendo a mãe, pôs-se a chorar. Fundindo-se em lágrimas, disse-lhe: 
- Meu marido não é um ser humano, é um ogro. Mãe, por que você veio até aqui? Se meu marido te ver, vai te devorar. Esconda-se no arbusto que ladeia a gruta. Assim, você talvez consiga escapar de sua crueldade.

A mãe de Fati Dara, seguindo a recomendação da filha, escondeu-se no arbusto que ladeava a gruta, sua casa. Um momento se passou. Então, uma brisa quente soprou. Ouviu-se um assobio estridente e a noite terminou de cair sobre a gruta. Ao assobio estridente seguiu-se um barulho medonho de terra retorcida. Uma luz jorrou dos olhos do gênio. Ele apareceu em sua natureza horrenda. A mãe de Fati, apavorada, tremeu como uma folha em seu esconderijo.

O gênio, assim que chegou, disse à mulher, Fati Dara:

- Sinto um cheiro humano.

Ele vasculhou os arredores da gruta e não teve dificuldade em encontrar a mãe da esposa. Agarrando-a pelo pescoço e entregando-a a sua filha, disse:

- Mulher, aqui está uma boa carne. Eu farei dela meu almoço de amanhã.

Fati, dilacerada pela dor, tentou apelar à compaixão do marido:

- Esta mulher é minha mãe. Não a reconhece? Foi ela que celebrou nosso casamento. Meu marido, meu bom marido, queira, por favor, poupar a vida de minha mãe.

O gênio, impassível, disse à sua mulher:

- Mulher, você está aqui para me obedecer. A carne da sua mãe deve ser melhor que as outras carnes. Amanhã, ao meio dia, eu farei dela um bom petisco.

O gênio, então, não escutou mais nada e entrou na gruta. Atirando-se sobre a cama, dormiu até a manhã seguinte. Ao acordar, antes de ir à caça, disse a Fati:

- Você se lembra do que eu disse? Eu já te dei a minha palavra final. Antes do meio dia, antes de eu voltar da caçada, você fará 
da carne da sua mãe uma boa refeição. Será por este prato que eu começarei meu almoço.

Sem pestanejar, com sua faca em punho, o gênio saiu. Virando-se para sua mulher, ele disse, decidido:

- Seja particularmente cuidadosa com meu almoço de hoje. Você tem tudo o que necessita: a boa carne de sua mãe.

Enfim, o gênio se foi. A mãe de Fati então disse-lhe:

- Em seu caldeirão gigante, coloque bastante manteiga e condimentos que cheirem bem. Quando seu marido vier, diga-lhe que se curve sobre o caldeirão para provar minha carne cozida ao ponto. Enquanto isso, encolhida sob a cama, eu vou surgir e vou empurrar o monstro na água fervente. Não tenha medo de nada, minha filha, eu vou te tirar daqui. Nada resiste ao amor de uma mãe. Em meu lugar, será o seu marido monstruoso que cozinhará em seu grande caldeirão.

Fati seguiu os conselhos da mãe. Tudo foi preparado como ela havia indicado. Fati, para passar o tempo, cantou esta canção:

- O pé que cozinha no caldeirão é o pé da minha mãe.

O braço que cozinha no caldeirão

é o braço da minha mãe.

A cabeça que cozinha no caldeirão é a cabeça da minha mãe.

Que Deus proteja minha mãe!

O gênio, furioso, intimou Fati a repetir sua canção. Obediente, ela retomou, mas com uma outra canção:

[14] Nome de uma árvore em língua Zarma. Esta nota encontra-se no texto original. Optamos por modificar a grafia da letra final "é" para "ê", de maneira a mantermos o efeito fonético presente no original.

[15] Idem.
- A madeira faz um fumacê, a madeira do "Sabarê"14

faz um fumacê, a madeira do Kokorbê ${ }^{15}$ faz um fumacê! É preciso tudo aquecer para ter o que comer. 
O gênio, louco de raiva, agarrou Fati pelo pescoço, pronto para jogá-la também no caldeirão fervente. Mas, prontamente, ela disse ao marido:

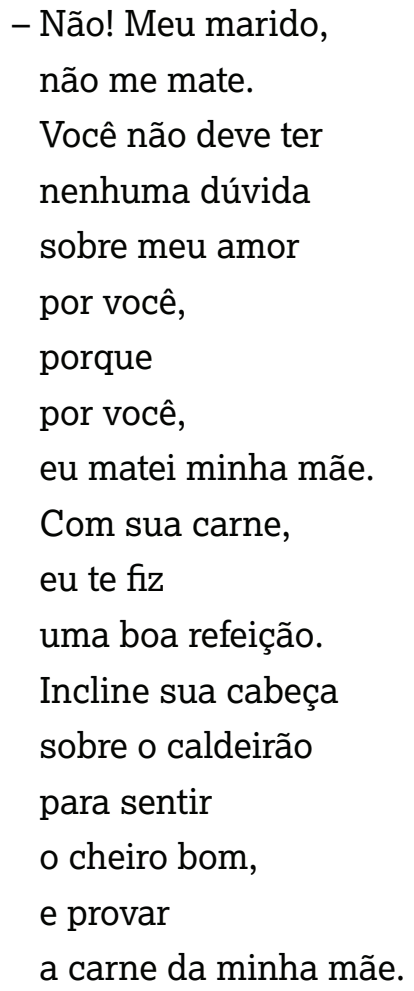

No auge da alegria, o gênio soltou um grunhido. Inclinando a cabeça sobre o caldeirão, soltou uma risada maléfica: "Hahaa! Hahaa! Hahaa!"

Enquanto isso, a mãe de Fati surgiu de seu esconderijo e, com todas as forças, empurrou o gênio no caldeirão fervente.

Tendo seu golpe sido bem sucedido, ela pegou a filha pela mão e tirou-a da gruta.

Mas, antes de ir, cortou um pedaço da carne do monstro com a intenção de mostrá-la às pessoas da vila.

Fati e sua mãe correram, depois caminharam por muito tempo antes de chegarem à vila. Na entrada, a mãe perdeu a carne do gênio, que, muitos meses depois, germinou e tornou-se uma carne vermelha e viva. Aqueles que dela comeram tornaram-se os "Tchierko", os feiticeiros devoradores de almas. ${ }^{16}$

Meu conto terminou! Ele lhes narrou a origem dos Tchierko, os feiticeiros devoradores de almas.

[16] Do original, traduziríamos literalmente "devoradores de duplos humanos", sendo que tais duplos referem-se, como explicado anteriormente, ao conceito de biya, comumente traduzido como "alma". 


\section{TEXTO ORIGINAL}

Il y a longtemps, très longtemps, à l'origine des temps, vivait dans un village Fati Dara, Fati au teint de cuivre clair. Elle était jolie, Fati.Elle était belle. Son teint incomparable était celui de la lune rose levée sur un firmament sans tache. Ses dents merveilleusement blanches avaient la couleur du lait. Ses longs cheveux ondulés lui retombaient sur les épaules. Bien prise dans ses vêtements de soie et de velours, ornée de ses bracelets d'or et d'argent, de ses bijoux de diamants scintillants, Fati était l'étoile du pays. Elle était devenue un miroir qui attirait dans son sillage les rois, les princes, les riches, les grand guerriers qui accouraient pour demander à ses parents sa main.

Mais, hélas, Fati était une fille difficile. Elle avait en tête trois énigmes et ne voulait se marier qu'à un homme capable de lui en donner la clé. Ces énigmes, les voici:

ํ- Quelle est dans le monde la femme qui n'a pas de co-épouse, qui ne l'admet pas et à laquelle personne ne songe à en proposer une?

$2^{\circ}$ - Quel est dans le monde l'être qui se cache dans l'eau quand il pleut?

3o - Quel est dans le monde ce qui est plus rapide que l'éclair, plus rapide qu'un clin d'oeil?

Les jeunes gens, les princes, les rois, les riches, les grands guerriers défilèrent devant Fati, la belle jeune fille. Certains d'entre eux furent repoussés à cause de leurs qualités physiques déplaisantes. Tous butèrent contre les trois énigmes.Ils furent tous éconduits.

Un génie, après ces échecs, décida d'épouser Fati Dara. Il se métamorphosa. Il changea sa nature d'ogre contre celle d'un jeune homme d'une beauté auprès de laquelle celle de la jeune fille ternissait.

Le génie eut beaucoup de peine à trouver Fati. Chaque villageois rencontré lui disait:

- Tu es beau, très beau, mais comme les autres candidats, tu buteras contre les trois énigmes de la jeune fille.

Le génie ne se laissa pas décourager par de tels propos. Il persista et finit par trouver Fati Dara. Celle-ci vit que le jeune homme était très beau. Elle était sur le point de lui accorder sa main quand sa mère lui rappela ses trois énigmes:

- Mets l'étranger à l'épreuve. Demande-lui la clé de tes trois énigmes. 
Mais la jeune fille, devant l'étranger, perdit l'usage de la parole. Elle était sous l'effect du coup de foudre qui tua en elle toute réaction. Elle demeura sans défense devant le bel étranger.

Pour la deuxième fois, la mère de Fati lui rappela les énigmes par lesquelles elle testait l'intelligence de ses prétendants.

Se souvenant de son principe, elle eut peur de poser les énigmes au bel étranger, craignant de le perdre au cas où il ne répoindrait pas correctement.

Sa mère, intervenant une troisième fois, lui dit:

- Ma fille, ton principe est sage. Il doit dominer ton choix. Demande à l'étranger de te donner la clé de tes trois énigmes. Ainsi, ma fille, tu jugeras de son intelligence.

Avec beaucoup d'hésitation, Fati rappela ses trois énigmes au bel étranger. Celui-ci, d'une intelligence peu commune, répondit:

ํ- La femme dans le monde qui n'a pas de co-épouse, qui ne l'admet pas et à laquelle personne ne songe à en proposer "est le chef". Celui-ci est toujours unique.

$2^{\circ}$ - L'être au monde qui se cache sous l'eau quand il pleut est le crapaud. Quand il pleut, celui-ci s'abrite de la pluie sous une flaque d'eau.

3ํ- - Dans le monde, ce qui est plus rapide que l'éclair, plus rapide qu'un clin d'oeil, est la pensée, celle qui se rapporte à la femme ou à l'homme qu'on aime.

Enthousiaste, la mère de Fati qui assistait à la conversation entre sa fille et le bel étranger, s'écria:

- C'est formidable! C'est formidable, ma fille, maintenant tu as un mari! Il est l'homme le plus beau du monde et son intelligence est d'une vivacité sans pareille.

La mère de Fati Dara parcourut le village, disant:

- Ma fille s'est trouvé un mari, un homme d'une beauté exceptionnelle et d'une intelligence sans égale. Sortez, gens du village, Fati Dara a rencontré l'homme qu'elle aime! Accourez, gens du village! Accourez, voisins, vieux et vieilles, griots et griotes! Venez nombreux assister au mariage de ma fille avec un homme d'une intelligence sans pareille et d'une extraordinaire beauté. 
Les gens du village, les vieux et les jeunes garçons, ainsi que les jeunes filles, les voisins et les voisines, les griots et les griotes, tous en fête, accoururent à la voix de la mère de Fati Dara. Sa concession fut remplie d'hommes et de femmes, de griots et de griotes en fête, de marabouts devant lesquels étaient ouverts de gros Corans.

On célébra le mariage de Fati Dara dans l'allégresse. Des colas, des boubous, de pagnes, des mouchoirs y furent distribués aux griots, aux griotes, aux vieux et aux vieilles, aux marabouts, à toute l'assistance éblouie par la largesse du bel étranger, le mari de Fati Dara.

Devant tant de magnificence, tant de moutons, de chèvres, de boeufs et de chameaux tués pour fêter le mariage de sa fille, la mère de Fati Dara exulta:

- Venez voir le mari de ma fille! Venez voir un homme d'une beauté sans égale, l'homme le plus intelligent du monde, le plus généreux des hommes. Venez voir Fati Dara et son mari, le couple le plus beau de la terre.

Le génie, dans cette atmosphère de fête et de victuailles, vécut quelques jours avec sa femme, la belle et difficile Fati Dara.

Mais comme tout a une fin, le bel étranger obtint l'autorisation d'emmener sa femme chez lui. Il la mit en croupe sur son cheval et l'emporta. Sur le chemin, le mari et sa femme parlèrent de leur mariage, du village, des prétendants malhereux que Fati Dara avait refusés, de la mère de la jeune fille, de leurs souvenirs et de leur lune de miel.

Le soleil monta un peu plus haut dans le ciel. Les deux époux avaient déjà franchi le domaine du village de Fati. Au-delà de celui-ci, ils traversèrent la savane après laquelle ils entrèrent dans une forêt épaisse.

Fati Dara, depuis longtemps, avait cessé de parler, de répondre à son mari particulièrement bavard au cours du voyage. Enfin, dans la profondeur de la forêt, le cheval du bel étranger s'arrêta devant une grotte. Fati Dara en descendit. Puis ce fut le tour de son mari de poser le pied à terre. Le cheval hennit et devint une girafe. Le bel étranger siffla et devint un génie difforme, infect, avec deux cornes sur la tête, des sabots fourchus, des ongles crochus, des crocs pendants comme des coupe-coupe tranchants, des cils et des sourcils tombant sur les joues comme des cheveux tressés et des oreilles larges semblables à celles d'un âne. Il se présenta à Fati Dara dans sa vraie nature, sans fard, dans sa réalité de génie, de vrai génie que Fati, à force de choisir, venait d'épouser pour le meilleur et pour le pire.

A la vue de l'horrible créature, Fati Dara, prise de panique, pleura. Elle ne cria pas. Elle laissa couler des larmes abondantes. 
Le monstre remua son corps couvert d'écailles, ses dents pendantes comme des coupe-coupe tranchants, ses grandes oreilles d'âne, ses cils et ses sourcils qui lui tombaient sur les joues.

Les sabots fouchus enfoncés dans le sol, hideux, il dit à sa femme:

- Femme, ne pleure pas. Je suis le roi de la brousse et lu en es la reine. Tu dois obéir à mes ordres. Les voici, ma femme. Tu es ma femme, tu es donc obligée de vivre avec moi. Chaque matin, j'irai à la chasse. Toi, tu resteras à la maison où tu t'occuperas de la cuisine. Je n'aime pas la trahison. Tu ne dois pas oublier non plus que tu es à six mois de marche de chez toi, loin de tout secours humain. Si tu t'avises de te sauver, je couvrirai en une heure la distance que tu peux parcourir en quinze jours de marche. Alors, ma belle, sois sage et fais ce que je te commanderai.

Le génie montrueux reprit sa tâche ordinaire. Chaque matin il allait à la chasse. Chaque jour, il ramenait un gibier qu'il donnait à sa femme. Faute de chair humaine, elle lui cuisait la viande du gibier.

Pendant douze mois, le ménage alla son train. Pendant ce temps, la mère de Fati, sans nouvelle de sa fille, perdit sa gaieté. Elle se morfondait dans sa chambre et ne sortait plus. D'abord inquiète, elle finit par désespérer.

Lasse d'attendre, elle prit une graine de courge. Elle l'ensorcela. Avant de la semer dans le sol humide, elle lui dit:

- Bonne graine de courge, bonne graine de Dieu, je vais te confier à la terre. Tu pousseras, bonne graine. Tu deviendras une tige. A la tige poussera une branche. Elle rampera sur le sol, loin, très loin, jusqu'à la maison de mon gendre, jusque chez ma fille.

La mère de Fati planta la graine de courge. Celle-ci poussa. Sa tige frêle sortit de la terre, émit une branche rampante qui s'étala sur le sol, loin, sur des kilomètres, très loin dans la brousse jusque son gendre, jusqu'à la grotte qui servait de maison à sa fille.

Ainsi, en deux mois, la plante couvrit la distance qui séparait la mère de Fati de sa fille. La mère suivit la branche rampante de la courge, des jours, des nuits, des mois. Enfin, elle arriva à la porte de la grotte où était recluse sa fille. Celle-ci, voyant sa mère, se mit à pleurer, à fondre en larmes. Elle lui dit:

- Mon mari n'est pas un être humain. C'est un ogre. Mère, pourquoi es-tu venue ici? Si mon mari te voit, il te mangera. Cache-toi dans 
le buisson qui borde la grotte. Ainsi, sans doute, tu échapperas à sa cruauté.

La mère de Fati Dara, comme le lui avait dit sa fille, se cacha dans le buisson qui bordait la grotte, sa demeure. Un moment s'écoula. Alors, un petit vent chaud souffla. On entendit un sifflement strident et la nuit acheva de tomber sur la grotte. Au sifflement strident succéda un bruit effroyable de terre qui se tord. Une lumière jaillit des yeux du génie.Il apparut dans sa hideuse nature. La mère de Fati, transie de peur, trembla comme une feuille dans sa cachette.

Le génie, dès qu'il arriva, dit à sa femme, Fati Dara:

- Je sens une odeur humaine.

Il fouilla les environs de la grotte. Il n'eut aucune peine à trouver la mère de sa femme. Il la saisit au cou. La remettant à sa fille, il lui dit:

- Femme, voici de la viande, de la bonne viande. J'en ferai mon déjeuner de demain.

Fati, déchirée par la douleur, tenta d'attendrir son mari:

- Cette femme est ma mère. Ne la reconnais-tu pas? C'est elle qui a célébré notre mariage. Veux-tu, mon mari, mon bon mari, épargner la vie de ma mère?

Le génie, impassible, dit à sa femme:

- Femme, tu es là pour m'obéir. La chair de ta mère doit être meilleure que les autres chairs. Demain, à midi, j'en ferai un bon petit repas.

Le génie n'écouta plus rien. Il entra dans sa grotte. Se jetant sur son lit, il s'endormit jusqu'au matin. A son réveil, avant d'aller à la chasse, il dit à Fati:

- Te souviens-tu de ce que j'ai dit? Je n'ai qu'une parole. Je te l'ai donnée. Avant midi, avant mon retour de la chasse, tu feras de la viande de ta mère un bon repas. Ce sera par ce plat que je commencerai mon déjeuner. 
Sans sourciller, son coutelas à la main, le génie sortir. Se tournant vers sa femme, il lui dit, décidé:

- Soinge particulièrement mon déjeuner de ce midi. Tu as tout ce qu'il le faut, la bonne chair de ta mère.

Enfin, le génie partir. La mère de Fati lui dit:

- Dans ta marmite géante, mets beacoup de beurre, de condimentes qui sentent bon. Quand ton mari viendra, tu lui diras de se pencher sur la marmite pour goûter ma chair cuite à point. Pendant ce temps, blottie sous le lit, j'en surgirai et je précipiterai le monstre dans son eau bouillante. Ne crains rien, ma fille, je te sortirai d'ici. Rien ne resiste à l'amour d'une mère. A ma place, c'est ton monstruex mari qui cuira dans ta grande marmite.

Fati suivit les conseils de sa mère. Tout fut préparé comme elle l'avait indiqué. Fati, pour passer le temps, chanta cette chanson:

- Le pied qui cuit dans la marmite est le pied de ma mère.

Le bras qui cuit dans la marmite est le bras de la mère.

La tête qui cuit dans la marmite est la tête de ma mère.

Que Dieu protège ma mère!

Le génie, furieux, somma Fati de répéter sa chanson. Obéissante, elle reprit, mais par une autre chanson. Elle dit:

- Le bois fait trop de fumée, le bois du "Sabaré"17 fait beaucoup de fumée, le bois du Kokorbé ${ }^{18}$

fait beaucoup de fumée!

Il faut tout brûler

pour avoir de quoi croquer.

Le génie, fou de rage, saisit Fati au cou, prêt à la jeter, elle aussi, dans la marmite bouillante. Mais, prompte, elle dit à son mari: 


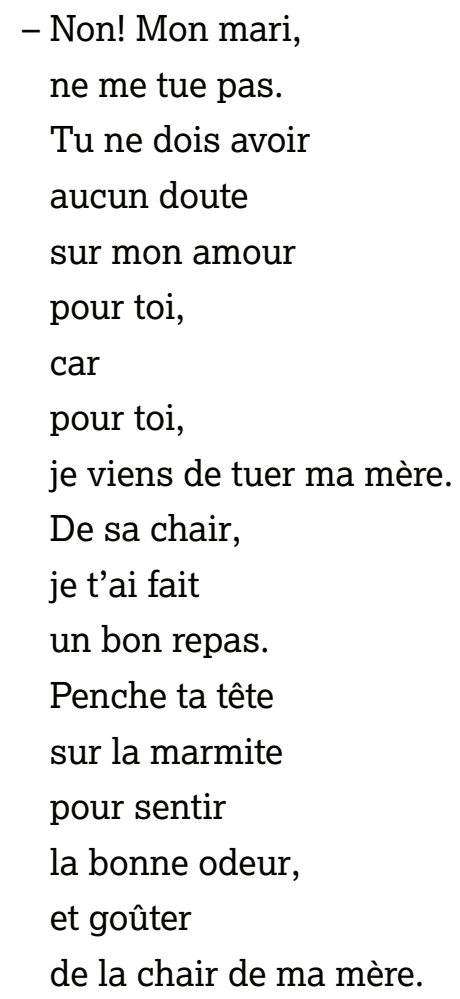

Au comble de la joie, le génie poussa un grognement. Penchant sa tête vers la marmite, il fit un vilain rire: "Hahaa! Hahaa! Hahaa!"

Pendant ce temps, la mère de Fati surgit de sa cachette. De toutes ses forces, elle poussa le génie dans la marmite bouillante.

Son coup réussi, elle prit sa fille par la main et la sortit de la grotte.

Mais, avant de s'en aller, elle coupa une tranche de la chair du monstre avec l'intention de la montrer aux gens de son village.

Fati et sa mère coururent, puis marchèrent longtemps avant de regagner le village.

A l'entrée de celui-ci, la mère de Fati perdit la chair du génie. La chair, plusieurs mois plus tard, germa.

Elle devint une chair rouge, vivante. Ceux qui enmangèrent devinrent les "Tchierko", les sorciers mangeurs de doubles humains.

Mon conte est fini! Il vous a dit l'origine des Tchierko, les sorciers mangeurs de doubles humains. 
ANA LUIZA DE OLIVEIRA E SILVA - Doutoranda em História Social pelo Departamento de História da Faculdade de Filosofia, Letras e Ciências Humanas - FFLCH, da Universidade de São Paulo - USP, São Paulo, SP. Bolsista CAPES, PDSE, processo 3348/2015-06. aluidos@usp.br.

\section{REFERÊNCIAS BIBLIOGRÁFICAS}

HAMA, Boubou. Contes et légendes du Niger. Tome I. Paris : Présence Africaine, 1972 Contes et légendes du Niger. Tome II. Paris : Présence

Africaine, 1972

Contes et légendes du Niger. Tome VI. Paris : Présence

Africaine, 1976

HAMPÂTÉ BÂ, Amadou. Amkoullel, o menino fula. São Paulo : Palas Athena :

Casa das Áfricas, 2003

HERNANDEZ, Leila Maria Gonçalves Leite. A África na sala de aula: visita à história contemporânea. $4^{a}$ ed. São Paulo : Selo Negro, 2008

O NOBRE ALCORÃO. Tradução de sentido para a língua portuguesa realizada por Dr. Helmi NASR, professor de Estudos Árabes e Islâmicos na Universidade de São Paulo. São Paulo : Centro Islâmico no Brasil, s/d

ROUCH, Jean. La religion et la magie songhay. [1960] $2^{e}$ édition revue et augmentée. Bruxelles : Éditions de l'Université de Bruxelles, 1989 
